\title{
Life style of patient before and after diagnosis of hypertension in Kathmandu
}

\author{
Radha Acharya ${ }^{1}$, Hom Nath Chalise ${ }^{2^{*}}$ \\ ${ }^{1}$ Department of Nursing, Kathmandu University School of Medical Sciences, Dhulikhel, Kavre; \\ ${ }^{2}$ Department of Public Health, Asian College for Advance Studies, Satdobato, Lalitpur; ${ }^{*}$ Corresponding Author: chalisehkpp@gmail.com
}

Received 20 April 2011; revised 30 May 2011; accepted 18 June 2011.

\begin{abstract}
Hypertension is an important public healthchallenge in the developing and the developed world alike. However, hospital-based studies on cardiovascular diseases including hypertension in a developing country like Nepal have been limited. Objective: The objective of the present study was to determine the life style of patients before and after diagnosis of hypertension. Methods: A total of $\mathbf{1 0 0}$ adult hypertensive patients over 30 years of age who were attending in medical out patients department within 6 month to 2 years after first diagnosis of hypertension in Shahid Gangalal National Heart Centre and Tribhuvan University Teaching Hospital, in Kathmandu, Nepal, in April 2009, were included using a descriptive research design. The data was collected by interview using a questionnaire consisting of a combination of structured and semi- structured questions. The data was analyzed by using SPSS $\mathbf{1 1 . 5}$ version. Results: This study found the respondents' knowledge regarding hypertension was poor. Regarding life style of hypertensive patients, majorities $(90 \%)$ of them were non-vegetarian before diagnosis but after diagnosis of hypertension the percentage of non-vegetarian was reduced by $10 \%$. Similarly, the reduction in consumption of meat, eggs, ghee and oil (mustard, sunflower) by hyperten- sive patients was statistically significant dif- ference $(p=0.000)$ after the diagnosis of hypertension. Regarding soya- bean oil consumption, additional salty food and amount of salt intake there was no statistical significant difference before and after the diagnosis of hypertension. Likewise, physical exercise and stress reduction activities performed by hypertensive patients and change in drinking alcohol and smoking was found to
\end{abstract}

be statistically significant difference $(p=0.000)$ after the diagnosis of hypertension. Conclusion: The adverse consequences of hypertension can be reduced by modifying the life style. Therefore more focus should be given in increasing the awareness about hypertension by developing information, education and communication materials on hypertension and setting up hypertensive counseling clinic in each hospitals.

Keywords: Hypertension; Lifestyle; Hypertensive Patient; Nepal

\section{INTRODUCTION}

About a quarter of the world's population have been estimated to have hypertension at the turn of the millennium. It has remained an important public health challenge in the developing and the developed world alike. The burden of chronic conditions such as hypertension has been likened to an iceberg phenomenon in which the cases that we see are only a part of the whole problem. Even within the 'visible' portion, there are different strata of hypertension with or without controlled blood pressure [1].

Hypertension has become one of the very common diseases in the modern society. It is the result of the mental tension and steeping into the highly sophisticated life style of the so-called modern society. Besides that lack of knowledge of the people on their food habit or diet intake has also played crucial role on the expansion of the disease. Likewise, increasing pace of urbanization and industrialization of the developing countries has contributed significant impact on accelerating the disease. It can be assumed that there is highly positive correlation between increased number of hypertension and the pace of modernization [1].

Hypertension is a major health burden and the leading cause of death in the world. Although hypertension is more common in economically developed countries than 
in economically developing ones, it is a greater population burden in the latter because of the much larger population. WHO estimated about $62 \%$ of cardiovascular disease and $49 \%$ of ischemic heart disease burden worldwide. Hypertension is estimated to cause 7.1 million deaths annually accounting for $13 \%$ of all deaths globally. Overall $26.4 \%$ adult world population was estimated to have hypertension in the year 2000, a number that was projected to increase to $29.2 \%$ by 2025 [2].

Certain life style habits, including unhealthy dietary habits, cigarette smoking and inactivity are risk factors for cardiovascular disease that in part may be mediated through effects on blood pressure and body weight. These life style factors may also be established during childhood and adolescence, however, their associations with weight status and blood pressure in childhood and adolescence are less clear than in adulthood [3].

The main objective of this study was to know what is the awareness of hypertensive patient about their disease and life style of patient before and after diagnosis of hypertension.

\section{METHODOLOGY}

This is a cross-sectional study. A face to face interview survey method using structured questionnaire was adopted for this survey.

\section{STUDY SITE AND STUDY POPULATION}

This study was conducted in 2008 in 100 hypertensive patients above 30 years of age in two hospitals namely Shahid Gangalal National Heart Centre and Tribhuvan University Teaching Hospital (TUTH) in Kathmandu. Respondents for this study were patients who were hypertensive since 6 month to 2 years (diagnosed cases of hypertension) and they were under the treatment regimen and who were attended in medical outpatient department and follow up treatment of hypertension in the above two hospitals. The patients were selected from OPD card and according to Diagnosis (isolated hypertension) by the Doctor.

Patients having associated disease like Heart disease, Kidney disease, Diabetes etc. were excluded. The study was conducted over a month period from first August to first September, 2008.

Purposively 100 respondents were taken as sample for this study. Among 100 patients, 15 patients were taken from those who attended TUTH (From 065/4/12 to 065/4/16 Bikram Sambat Nepali Calendar) and 85 from SGNHC (From 065/4/17 to 065/5/6 Bikram Sambat Nepali Calendar). Only few patients were taken from TUTH due to lesser number of hypertensive patients attending this hospital. For the selection of respondents, Out Patient Department files of the hypertensive patients were analyzed. And the first hundred patients whose file met the requirement were taken as the sample. All the patients meeting the criteria were interviewed on first come first basis till 100 samples were met.

\subsection{Ethical Consideration}

The study was conducted after receiving approval from the Thesis Committee of Maharajgunj Nursing Campus, Tribhuvan University. Before we started our study a written permission was obtained from the concerned authorities of the selected hospitals for this study. The study respondents were adequately informed and explained about the purposes of the study. They were assured of the privacy and confidentiality of the information. So, verbal informed consent was obtained before a respondent was interviewed which is quite common in previous study too $[4,5]$.

\subsection{Data Analysis}

SPSS 11.5 version soft ware was used to analyze the data. First, distribution in the form of frequencies and percentages, and measures of central tendency for all independent and dependent variable were reviewed. Chisquare test was done to compare the life style modification before and after diagnosis of hypertension and p-value $<0.05$ was considered as significant.

\section{RESULTS}

Table 1 shows the socio-demographic characteristics of the study population. Age distribution of the respondents shows that age ranged from 31 years to 76 years with mean (SD) age 51.26 (0.78). Similarly, 57\% were male and $43 \%$ were female. According to the location of the respondents, 64\% were urban and 36\% were from rural area. Among the four religious groups, $80 \%$ respondents were Hindus. Similarly in the ethnic composition of the respondents, 32\% were Newars, 30\% Brahmins, $15 \%$ Mongolian and $7 \%$ Terai cast. In the educational level, 31\% were illiterate, 79\% were literate among them 35\% had higher secondary and above education status. As per the occupational distribution of the respondents, $42 \%$ from house hold work sector, 25\% from service sector, $17 \%$ from business and $16 \%$ were from the agriculture sector. Economic status of respondents was measured on the basis of food sufficiency to eat. $10 \%$ respondents do not have sufficient food for a year, $60 \%$ have sufficient for a year and 30\% respondents have some saving also. Duration of Hypertension shows that majority of the respondents were suffering from one to two year and $20 \%$ were suffering from six to one year. 
Table 1. Socio-demographic characteristics of the hypertensive patients $(n=100)$.

\begin{tabular}{|c|c|c|}
\hline Variables & Number & Percent \\
\hline \multicolumn{3}{|c|}{ Age Group } \\
\hline $31-40$ & 18 & 18 \\
\hline $41-50$ & 34 & 34 \\
\hline $51-60$ & 25 & 25 \\
\hline Above 60 & 23 & 23 \\
\hline \multicolumn{3}{|c|}{ Mean age 51.26 (minimum 31 maximum 76) } \\
\hline \multicolumn{3}{|c|}{ Sex } \\
\hline Male & 57 & 57 \\
\hline Female & 43 & 43 \\
\hline \multicolumn{3}{|c|}{ Marital Status } \\
\hline Unmarried & 2 & 2 \\
\hline Married & 91 & 91 \\
\hline Widow & 7 & 7 \\
\hline \multicolumn{3}{|c|}{ Residence } \\
\hline VDC & 36 & 36 \\
\hline Municipality & 64 & 64 \\
\hline \multicolumn{3}{|c|}{ Religion } \\
\hline Hindu & 80 & 80 \\
\hline Buddhist & 14 & 14 \\
\hline Christian & 4 & 4 \\
\hline Kirant & 2 & 2 \\
\hline \multicolumn{3}{|c|}{ Ethnicity } \\
\hline Brahmin & 30 & 31 \\
\hline Chhetri & 16 & 16 \\
\hline Newar & 32 & 32 \\
\hline Mongolian & 15 & 15 \\
\hline $\begin{array}{c}\text { Teraicastes(Shah, Gup- } \\
\text { ta, Chaudhary) }\end{array}$ & 7 & 7 \\
\hline \multicolumn{3}{|c|}{ Educational Status } \\
\hline Illiterate & 31 & 31 \\
\hline $\begin{array}{l}\text { Literate(Non formal } \\
\text { education) }\end{array}$ & 10 & 10 \\
\hline Primary & 8 & 8 \\
\hline Secondary & 16 & 16 \\
\hline $\begin{array}{c}\text { Higher secondary and } \\
\text { above }\end{array}$ & 35 & 35 \\
\hline \multicolumn{3}{|c|}{ Occupation } \\
\hline Agriculture & 16 & 16 \\
\hline Business & 17 & 17 \\
\hline Service & 25 & 25 \\
\hline House hold work & 42 & 42 \\
\hline \multicolumn{3}{|c|}{ Economic Status } \\
\hline $\begin{array}{l}\text { Not sufficient to eat for } \\
1 \text { year }\end{array}$ & 10 & 10 \\
\hline $\begin{array}{c}\text { Sufficient to eat for } 1 \\
\text { Year }\end{array}$ & 60 & 60 \\
\hline Extra saving & 30 & 30 \\
\hline \multicolumn{3}{|c|}{ Family Type } \\
\hline Nuclear & 53 & 53 \\
\hline Joint & 31 & 31 \\
\hline Extended & 16 & 16 \\
\hline \multicolumn{3}{|c|}{ Duration of Hypertension } \\
\hline 6 month - 1 years & 20 & 20 \\
\hline 1 year - 2 years & 80 & 80 \\
\hline
\end{tabular}

The respondents were asked about hypertension but they have poor knowledge regarding its causes, sign and symptoms, control measure and complications. Among the total respondents 31\% answered excessive salt and fat intake as the factors leading to disease occurrence followed by stress/tension (24\%), smoking/alcohol (10\%) and five percent answered over weight and heredity (Table 2). Further 55\% respondents answered main symptoms of hypertension was dizziness (55\%) followed by Headache (47\%), Fatigue (18\%), Palpitation (8\%), Blurred vision (7\%), and Flushing face (6\%).

Out of total respondents, majority $(63 \%)$ of the respondents reported that taking medicine can help the control of blood pressure. Similarly, 49\% respondents reported taking low salt and low fat diet is to control blood pressure. Few (3\%) of them reported weight reduction can help to control the blood pressure (Table 3). Regarding the complication related with hypertension $42 \%$ respondents reported heart attack followed by paralysis (26\%), kidney disease (15\%), stroke (10\%) and blindness (5\%) (Table 3).

Regarding the food habit of respondents, majorities (90\%) of respondents were non-vegetarian and only $10 \%$ were vegetarian before diagnosis, whereas after diagnosis of hypertension, vegetarian were found to have increased from $10 \%$ to $20 \%$, which is not shown here in the table.

Table 4 shows the change in frequency of meat and eggs consumed by non-vegetarian after diagnosis of hypertension. Majority of respondents (81\%) used to take mutton before diagnosis and it reduced to $59 \%$ after diagnosis. After diagnosis of hypertension, daily consumers reduced from $17 \%$ to $5 \%$ and weekly consumers from 42 to 18 where as occasional consumers increased from $22 \%$ to $30 \%$. Similarly pork consumers declined from 16 to $8 \%$, chicken consumers declined from $76 \%$

Table 2. Awareness on symptoms and factors that may lead to hypertension $(\mathrm{n}=100)$.

\begin{tabular}{|c|c|}
\hline Symptoms/factors & Number (\%) \\
\hline \multicolumn{2}{|c|}{ Symptoms } \\
\hline Dizziness & $55(55)$ \\
\hline Headache & $47(47)$ \\
\hline Fatigue & $18(18)$ \\
\hline Epistaxis & $2(2)$ \\
\hline Blurred vision & $7(7)$ \\
\hline Palpitation & $8(8)$ \\
\hline Flushing face & $6(6)$ \\
\hline \multicolumn{2}{|c|}{ Disease causing factors } \\
\hline Over weight & $5(5)$ \\
\hline Heredity & $5(5)$ \\
\hline Smoking/alcohol & $10(10)$ \\
\hline Excessive salt and fat intake & $31(31)$ \\
\hline Stress/tension & $24(24)$ \\
\hline
\end{tabular}


Table 3. Awareness on complication and control measure of hypertension, $\mathrm{n}=100$.

\begin{tabular}{cc}
\hline Complication and awareness & Number (\%) \\
\hline Complications of Hypertension & \\
Heart attack & $42(42)$ \\
Kidney disease & $15(15)$ \\
Blindness & $5(5)$ \\
Stroke & $10(10)$ \\
Other (paralysis) & $26(26)$ \\
Control measures & \\
Reducing weight & $3(3)$ \\
Low salt and low fat diet & $49(49)$ \\
Stop smoking & $11(11)$ \\
Regular exercise & $27(27)$ \\
Reducing stress & $22(22)$ \\
Taking medicine & $63(63)$ \\
\hline
\end{tabular}

Table 4. Type of meat and eggs consumed by respondents $(\mathrm{n}=$ 90).

\begin{tabular}{|c|c|c|c|c|c|}
\hline \multirow{2}{*}{$\begin{array}{c}\text { Variables } \\
\text { Type of } \\
\text { Meat }\end{array}$} & \multicolumn{4}{|c|}{ Frequency of consumption } & \multirow[t]{2}{*}{$\begin{array}{c}\text { Chi-square } \\
\text { p-value }\end{array}$} \\
\hline & Daily & Weekly & Occasionally & Total & \\
\hline \multicolumn{6}{|c|}{ Mutton } \\
\hline $\begin{array}{l}\text { Before } \\
\text { diagnosis }\end{array}$ & $\begin{array}{c}17 \\
(19 \%)\end{array}$ & $42(47 \%)$ & $22(24 \%)$ & $81(90 \%)$ & \multirow{2}{*}{0.000} \\
\hline $\begin{array}{c}\text { After } \\
\text { diagnosis }\end{array}$ & $5(6 \%)$ & $18(20 \%)$ & $30(33 \%)$ & $53(59 \%)$ & \\
\hline \multicolumn{6}{|c|}{ Pork } \\
\hline $\begin{array}{l}\text { Before } \\
\text { diagnosis }\end{array}$ & $1(1 \%)$ & $5(6 \%)$ & $8(9 \%)$ & $14(16 \%)$ & \multirow{2}{*}{0.000} \\
\hline $\begin{array}{c}\text { After } \\
\text { diagnosis }\end{array}$ & - & $2(3 \%)$ & $5(6 \%)$ & $7(8 \%)$ & \\
\hline \multicolumn{6}{|c|}{ Chicken } \\
\hline $\begin{array}{l}\text { Before } \\
\text { diagnosis }\end{array}$ & $\begin{array}{c}26 \\
(29 \%)\end{array}$ & $38(42 \%)$ & $12(13 \%)$ & $76(84 \%)$ & \multirow{2}{*}{0.000} \\
\hline $\begin{array}{c}\text { After } \\
\text { diagnosis }\end{array}$ & $\begin{array}{c}15 \\
(17 \%)\end{array}$ & 32 (36\%) & 21 (23\%) & $68(76 \%)$ & \\
\hline \multicolumn{6}{|c|}{ Fish } \\
\hline $\begin{array}{l}\text { Before } \\
\text { diagnosis }\end{array}$ & - & $6(7 \%)$ & $16(18 \%)$ & $22(24 \%)$ & \multirow{2}{*}{0.000} \\
\hline $\begin{array}{c}\text { After } \\
\text { diagnosis }\end{array}$ & - & $5(6 \%)$ & 12 (13\%) & 17(19\%) & \\
\hline \multicolumn{6}{|c|}{ Eggs } \\
\hline $\begin{array}{c}\text { Before } \\
\text { diagnosis }\end{array}$ & $\begin{array}{c}35 \\
(39 \%)\end{array}$ & $24(27 \%)$ & $26(29 \%)$ & $85(94 \%)$ & \multirow{2}{*}{0.000} \\
\hline $\begin{array}{c}\text { After } \\
\text { diagnosis }\end{array}$ & $\begin{array}{c}14 \\
(16 \%)\end{array}$ & $25(28 \%)$ & $25(28 \%)$ & $64(71 \%)$ & \\
\hline
\end{tabular}

to $68 \%$, fish consumption from $22 \%$ to $17 \%$ and egg from $94 \%$ to $71 \%$. The table also shows the frequency item consumption also declined after the diagnosis of hypertension. The change in food pattern after the diagnosis of hypertension was statistically significant (Pvalue $=0.000$ ).

Table 5 shows the changing pattern of oil and ghee consumed by the respondents after diagnosis of hypertension. Majority (79\%) of respondents used animal ghee before diagnosis. After diagnosis of hypertension daily users were found to have shifted occasional and non users. Hence, non users found increased from 21\% to $67 \%$ after diagnosis. Similarly vegetable ghee users also changed from occasion to non-users after the diagnosis of hypertension.

Most of the respondents used mustard oil before diagnosis of hypertension. After the diagnosis of hypertension the daily users reduced from $76 \%$ to $41 \%$ and weekly and occasional users shifted to non users. After the diagnosis of hypertension $59 \%$ discontinued the mustard oil.

The number of soybean oil consumers before diagnoses were $18 \%$ and after diagnosis increased from $18 \%$ to $26 \%$ in daily users. Very few respondents were occasional users. The use of soybean oil shows insignificant association ( $\mathrm{p}$-value $=0.281$ ) with change in oil consumption after the diagnosis of hypertension.

Out of total respondents, only 5\% respondents used sunflower oil daily and the number of daily user sharply increased from $5 \%$ to $29 \%$ after diagnosis of hypertension. There was statistically significant increase in the consumption of sunflower oil after the diagnosis of hypertension.

Out of total respondents, majority (54\%) had taken normal (as usual) salt, $41 \%$ were found taking additional or above normal and only 5\% were taking low salt before diagnosis. But after diagnosis, majority (65\%) had taken low salt, 33\% usual and $2 \%$ had taken additional salt. The change in the amount of consumption of salt after the diagnosis was not statistically significant $(\mathrm{p}=$ 0.431) (Table 6).

Additional salty food comprises papad, bottle pickle and potatochips/dalmoth etc. Out of total respondents, $76 \%$ were found to be using additional salty food before diagnosis and $60 \%$ still used it after the diagnosis. There was no statistically significant difference in consumption of additional salty food after the diagnosis.

Table 7 shows the smoking and alcohol consumption of respondents before and after diagnosis of hypertension. Out of total respondents $44 \%$ smoked before diagnosis and it reduced to $35 \%$ after diagnosis of hypertension. There was statistically significant difference $(p=$ 0.000 ) in smoking habit after the diagnosis of hypertension. After diagnosis of hypertension many respondents decreased the frequency of smoking. Similarly $60 \%$ respondents consumed alcohol before diagnosis. Among them daily users were $33 \%$, weekly $3 \%$ and occasional users were $24 \%$. However, $70 \%$ respondents did not consume alcohol after the diagnosis of hypertension. Only $12 \%$ respondents consumed alcohol daily, $4 \%$ weekly 
Table 5. Type of ghee and oil consumed by respondents, $(n=100)$.

\begin{tabular}{|c|c|c|c|c|c|}
\hline \multicolumn{6}{|c|}{ Frequency of consumption } \\
\hline Type of Ghee/Oil & Daily & Weekly & Occasionally & Non-user & Chi-square p-value \\
\hline Ghee (animals) & & & & & \\
\hline Before diagnosis & $57(57 \%)$ & - & $22(22 \%)$ & $21(21 \%)$ & \multirow{2}{*}{$0.008^{* *}$} \\
\hline After diagnosis & $15(15 \%)$ & - & $18(18 \%)$ & $67(67 \%)$ & \\
\hline \multicolumn{6}{|l|}{ Ghee (vegetables) } \\
\hline Before diagnosis & $1(1 \%)$ & - & $14(14 \%)$ & $85(85 \%)$ & \multirow[b]{2}{*}{$0.028 *$} \\
\hline After diagnosis & - & - & $3(3 \%)$ & 97 (97\%) & \\
\hline \multicolumn{6}{|l|}{ Mustard Oil } \\
\hline Before diagnosis & $76(76 \%)$ & $2(2 \%)$ & $22(22 \%)$ & $100 \%$ & \multirow[b]{2}{*}{$0.013 * *$} \\
\hline After diagnosis & $41(41 \%)$ & - & - & $59(59 \%)$ & \\
\hline \multicolumn{6}{|l|}{ Soyabean Oil } \\
\hline Before diagnosis & $18(18 \%)$ & - & $3(3 \%)$ & 79 (79\%) & \multirow[b]{2}{*}{0.281} \\
\hline After diagnosis & $26(26 \%)$ & - & $2(2 \%)$ & 72 (72\%) & \\
\hline \multicolumn{6}{|l|}{ Sunflower Oil } \\
\hline Before diagnosis & $5(5 \%)$ & - & $1(1 \%)$ & 94 (94\%) & \multirow[b]{2}{*}{$0.038 *$} \\
\hline After diagnosis & $29(29 \%)$ & $2(2 \%)$ & $3(3 \%)$ & $66(66 \%)$ & \\
\hline \multicolumn{6}{|l|}{ Butter } \\
\hline Before diagnosis & $1(1 \%)$ & $1(1 \%)$ & $10(10 \%)$ & 88 (88\%) & \multirow[t]{2}{*}{$0.000^{* *}$} \\
\hline After diagnosis & - & - & $3(3 \%)$ & 97 (97\%) & \\
\hline
\end{tabular}

** Significant at 0.01 level *Significant at 0.05 level.

Table 6. Amount of salt taken by hypertensive respondents $(n=100)$.

\begin{tabular}{ccccc}
\hline Amount of salt intake & Low & Normal & Additional & \multirow{2}{*}{ P-Value } \\
Before diagnosis & $5(5 \%)$ & $54(54 \%)$ & $41(41 \%)$ & 0.431 \\
After diagnosis & $65(65 \%)$ & $33(33 \%)$ & $2(2 \%)$ & \\
\hline
\end{tabular}

Table 7. Smoking and alcohol consumption habit of respondents.

\begin{tabular}{cccc}
\hline Smoking and drinking & Yes & No & P-Value \\
\hline Smoking & & & \\
Before diagnosis & $44(44 \%)$ & $56(56 \%)$ & 0.000 \\
After diagnosis & $35(35 \%)$ & $65(65 \%)$ & \\
Drinking & & $40(40 \%)$ & 0.000 \\
Before diagnosis & $60(60 \%)$ & $70(70 \%)$ & \\
After diagnosis & $30(30 \%)$ &
\end{tabular}

and $14 \%$ were taking it occasionally. The overall trend of the alcohol intake seems notably declining over the incidence in terms of both amount and frequency of intake although it is not shown here in detail. There was statistically significant ( $p=0.000$ ) reduction in consumption of alcohol before and after diagnosis of hypertension.

Physical exercise and stress reduction activities are important to control the hypertension. Out of total respondents, 23 had done physical exercise before diagnosis of hypertension. But after diagnosis; the number increased from $23 \%$ to $47 \%$. Similarly, very few 11 respondents had stress reduction activities before the di- agnosis of hypertension and their number increased remarkably from $11 \%$ to $39 \%$ after diagnosis of hypertension. There was statistically significant $(p=0.000)$ increase in performance of physical exercises and stress reduction activities after the diagnosis of hypertension (Table 8).

\section{DISCUSSION}

Hypertension is one of the most common disease affecting humans worldwide. Hypertension is the risk factor for coronary heart disease, stroke, congestive heart failure, end-stage renal disease, and peripheral vascular disease. Thus it has become a challenge for the health 
Table 8. Physical exercises and stress reduction activity performed by respondents.

\begin{tabular}{cccc}
\hline Control measures & Yes & No & P-Value \\
\hline \multirow{3}{*}{ Physical exercise } & \\
Before diagnosis & $23(23 \%)$ & $77(77 \%)$ & 0.000 \\
After diagnosis & $47(47 \%)$ & $53(53 \%)$ & \\
& Stress reduction activity & \\
Before diagnosis & $11(11 \%)$ & $89(89 \%)$ & 0.015 \\
After diagnosis & $39(39 \%)$ & $61(61 \%)$ & \\
\hline
\end{tabular}

care professionals to identify and treat this disease.

This study used adult hypertensive patients above 30 yrs of age from two hospital of Kathmandu. Mean age of the respondents was $51.26( \pm 0.78)$ years. Male patients (57\%) exceeded female patients. Similarly, majority patients belonged to nuclear family and had sufficient resources to eat for a year, but majority of them had no savings.

Men tend to display higher blood pressure than women, more evident in young and middle-age. This corresponds to the incidence and prevalence of hypertension in Nepal, as majority of hypertension is found to affect middle adult population. The prevalence of hypertension and the blood pressure levels increased with age in both men and women [6].

According to the location of the case, urban residents (64\%) were more vulnerable to hypertension than rural residents (36\%). An epidemiological study by Gupta and Sharma (2007), showed similar result with $25 \%$ urban and $10 \%$ rural subjects in India had hypertension. In developed countries prevalence of hypertension has been noted high in lower socio-economic groups whereas in societies with transitional state of economy high prevalence of hypertension has been noted [7].

The findings of the present study also suggest that hypertensive patients are not sufficiently aware about hypertension regarding its causes, signs and symptoms, control measures and complications. Familoni (2005) studied on knowledge and awareness of hypertension among patients with systemic hypertension in Nigeria which showed inadequate knowledge of hypertension in patients with hypertension in Nigeria. Among 254 patients, only one third knew that hypertension should be treated for life while $58.3 \%$ believed that antihypertensive drugs should be used only when there is a symptom [8].

Sharma et al. (2006) studied of prevalence, awareness, and control of hypertension in a suburban area of Kathmandu, Nepal. This study showed prevalence of hypertension is significant in Nepal and awareness, treatment and control rates are poor [9]. Another study carried out by Dong et al. (2007) in China also showed high prevalence of hypertension in rural adults in north east China with low rate of awareness and control [10].

The result of this study shows majority (90\%) of respondents were non-vegetarian before diagnosis, whereas after the diagnosis of hypertension vegetarian were found to have increased from $10 \%$ to $20 \%$. The change in food pattern after the diagnosis was statistically sig- nificant $(\mathrm{p}=0.000)$. Many literatures have been published supporting the usefulness of vegetarian diet for the hypertensive patients. A research study done by Lindhal (2006) found that vegetarian diet was extremely beneficial for hypertensive patients [11].

The consumption habit of non vegetarian items such as mutton, buff, pork, chicken, fish and eggs were taken into account while collecting the data. There was a sharp reduction in the consumption of meat items after diagnosis of hypertension. There was statistically significant decline in consumption of meat and eggs after the diagnosis of hypertension.

The study by Guba\& Lincoln, 2008, The Dietary Approaches to Stop Hypertension (DASH) diet is a diet rich in fish, chicken, lean meat, low-fat dairy, fruits, vegetables, whole grains, legumes, nuts, and seeds. In a highquality randomize control trials the DASH diet lowered SBP for hypertensive patients by an average of $11 \mathrm{~mm}$ $\mathrm{Hg}$ and DBP by an average of $5.5 \mathrm{~mm} \mathrm{Hg}$ compared with the control group [12].

According to study by MacGregor (2003) it was estimated that a reduction of $3 \mathrm{~g} / \mathrm{d}$ in salt intake would lower blood pressure by $2.5 / 1.4 \mathrm{mmHg}$, which would reduce strokes by 12 to $14 \%$ and ischaemic heart disease by $9 \%$ to $10 \%$ and could prevent about 7,300 to 8,300 stroke deaths and 10,600 to 12,400 ischemic heart disease deaths in the UK per year [13].

The number of respondents drinking alcohol declined to $30 \%$ from $60 \%$. The trend of the alcohol intake notably declined over the period both in terms of amount and frequency of intake. A study (WHO, 2006) observed a consistent association between alcohol intake and high blood pressure. There was statistically significant difference in consumption of alcohol before and after diagnosis of hypertension. Out of total respondents, $44 \%$ had a habit of smoking before diagnosis. But after diagnosis of hypertension $9 \%$ of them changed their habit. As a result the number of smokers declined to $35 \%$. There was no statistically significant difference in number of sticks used by the smoker after the diagnosis of hypertension.

Physical factors have been taken as one of the associated factors for the hypertension. After the diagnosis of hypertension, the number of respondents doing physical 
exercise increased to $47 \%$ from $23 \%$. Similar findings were also reported by Regmi (2008). He found that walking an hour per day at the rate of $4 \mathrm{~km} /$ hour to be an effective exercise for reducing hypertension [14].

Another study (WHO, 2006) also showed that there is an inverse relationship between an aerobic physical activities and blood pressure. Regular aerobic physical activity has been demonstrated to be beneficial both for prevention and treatment of hypertension [15]. In this study very few respondents had gone through stress reduction activities before diagnosis but after that number increased to 39\%.There was statistically significant difference between change in performance of physical exercises and stress reduction activities after the diagnosis of hypertension.

\section{THE LIMITATIONS OF THE STUDY}

The result of the study does not represent the whole population because it is a small scale hospital based study limited to the patients coming to TUTH and Shahid Gangalal National Heart Centre during the short period of data collection. The sample size also not estimates by calculating formula. Hence the results may not be generalized. This study was not designed randomly; hence this might possibly affect the results. There might be recall bias for questions asking about past life style (especially if diagnosed quite earlier). Regarding meat, oil/ghee and salt consumption, amount was not included in the questionnaire. Similarly time was not specified for physical exercise.

\section{CONCLUSIONS}

From this study, the awareness of hypertensive patients about their disease was found to be very poor. Regarding the change in life style, there was statistically significant difference on the type of food consumption including meat, eggs, ghee and oil. However there was no significant difference in soyabean oil consumption, additional salty food and amount of salt intake after the diagnosis of hypertension. There was statistically significant difference in certain types of physical exercises as swimming/cycling and yoga but not in walking, jogging/jumping and meditation. Similarly, there was statistically significant difference in consumption of alcohol and smoking habit.

Hence, it can be concluded that the awareness level of hypertensive patients is still low. The modification of life style is satisfactory for most risk factors, except for few like salt intake, additional salty food and number of sticks of cigarettes smoking. So Focus should also be given on modification of lifestyle for reducing the ad- verse consequences of hypertension. This can be done by: Mobilizing the key informants' e.g. political leader, social workers for public awareness, Broadcasting program and information regarding hypertension, Developing IEC (Information, Education and Communication) material (e.g. pamphlet, poster) which helps in prevent and control of hypertension and Setting up a hypertension-counseling clinic in each hospital to be launched by the trained nurses.

\section{REFERENCES}

[1] Eliot, H.L. and Esbensen, B.A (2003) Blood pressure, life style and treatment. Journal of Hypertension, 13, 1093-1099.

[2] Gupta, R. and Singh, N. (2006) Meta-analysis of prevalence of hypertension in India. Indian Heart Journal, 10, 465-472.

[3] Biel, K. (2008) Hypertension and stroke in Asia: Prevalence, control and strategies in developing countries. Journal of Human Hypertension, 22, 441-443.

[4] Chalise, H.N., Saito, T. and Kai, I. (2010) Social support and its correlation with loneliness: A cross-cultural study of Nepalese older adults. International Journal of Aging and Human Development, 71, 115-137. doi:10.2190/AG.71.2.b

[5] Chalise, H.N., Saito, T., Takahashi, M. and Kai, I. (2007) Relationship specialization amongst sources and receivers of social support and its correlations with loneliness and subjective well-being: A cross-sectional study of Nepalese older adults. Archives of Gerontology and Geriatrics, 44, 299-314. doi:10.1016/j.archger.2006.07.001

[6] Sarraf-Zadegan, N., Boshtam, M., Mostafavi, S. and Rafiei, M. (1999) Prevalence of hypertension and associated risk factors in Isfahan, Islamic Republic of Iran. Eastern Mediterranean Health Journal, 5, 993-1001.

[7] Gupta, R. and Sharma, A.R. (2007) Prevention of hypertension and subtypes in an Indian Rural population: Clinical and electrocardiographic correlates. Indian $\mathrm{He}$ art Journal, 8, 823-829.

[8] Familoni, B. (2005) Knowledge and awareness of hypertensionamong patients with systemic hypertension in Nigeria. Journal of Clinical Hypertension, 21, 450-462.

[9] Sharma Dewakar, K.C., et al. (2006). Study of prevalence, awareness, and control of hypertension in a suburban area of Kathmandu, Nepal. Indian Heart Journal, 58, 34-37.

[10] Dong, G.H. and Sun, Z.Q. (2007) Awareness, treatment and control of hypertension in rural adults of China. Journal of Hypertension Residence, 30, 951-958. doi:10.1291/hypres.30.951

[11] Lindhal, R.S. (2006) Vegetarian diet for hypertensive patient. New England Journal of Medicine, 330, 15301533

[12] Guba, E.G. and Lincoln, Y.S. (2008) Hypertension the role of diet and lifestyles. Journal of Human Hypertension, 15, 235-251.

[13] MacGregor, D.E. (2003) How far should salt intake be 
reduced? Recommendation on dietary salt. American Journal of Medical Association, 28, 59-64.

[14] Regmi, S. (2008) Detection of individuals prone to develop hypertension in the future life. Journal of Nepal
Medical College, 10, 33-37.

[15] World Health Organization (2006) Focus in priorities, WHO report, 2005. www.who.org 